To the Editors:

\title{
Re: Outcome after revascularisation of marginally viable limbs and dead limbs following lower limb arterial injuries Ceylon Medical Journal 2017; 62: 203-204
}

\section{Anton S Dias Perera}

Ceylon Medical Journal 2018; 63: 95

DOI: http://doi.org/10.4038/cmj.v63i2.8689

I read the above research letter with great interest. The author is commended for the commitment to limb salvage and extending vascular care in a regional medical center in Sri Lanka. However, there are several clinical, ethical and terminological issues that are worth addressing.

In order to allow scientific comparison and scrutiny, an acutely ischemic limb must be defined and classified according to established clinical criteria using Rutherford classification (class I, II and III) The Mangled Extremity Severity Score (MESS) should be included to define the extent of soft tissue (skin, muscle and nerve) and bone injuries in the setting of arterial ischemia due to highvelocity injury or severe blunt trauma. A patient with Rutherford class III ischemia will be at prohibitively high risk of reperfusion injury following revascularization. Therefore, primary amputation is considered a safer alternative for these patients. However, for a patient with Rutherford class IIB ischemia, an immediate revascularization procedure is required. Limb salvage is often futile in patients with a mangled extremity (MESS score <7).

The author has classified his patients into two groups: viable and marginally viable/dead. He does not provide supporting clinical criteria for this classification. However, I would include any limb considered to be dead or marginally viable in Rutherford class III. Numerous studies, including a recent study by Taha et al from the University of Pittsburg, have presented strong evidence against revascularization in patients with Rutherford Class III ischemia. The data presented here lack robustness to suggest otherwise.

\section{References}

1. Earnshaw JS. Acute limb ischemia: evaluation and decision making. In: Cronenwett JL, Johsnton KW, editors. Rutherford's vascular surgery. 8th ed. Philadelphia: Elsievier Saunders; 2014. p 2518-2522.

2. Kauvar DS, Kraiss LW. Mesenteric vascular disease: acute ischemia. Vascualr trauma: extremity. In: Cronenwett JL, Johsnton KW, editors. Rutherford's vascular surgery. 8th ed. Philadelphia: Elsievier Saunders; 2014. p 2485-2490.

3. Taha A, Byrne RM, Avgerinos ED, Marone LK, Makaroun MS, Chaer RA. Comparative effectiveness of endovascular versus surgical revascularization for acute lower extremity ischemia. J Vasc Surg 2015; 61:147-54.

University of Tennessee, and Vascular Surgeon, Baptist Memorial Hospital, Memphis, Tennessee, U.S.A. Correspondence: ASDP, e-mail: <surathdp@gmail.com>. Received 17 December 2017. distribution, and reproduction in any medium, provided the original author and source are credited. 